\title{
Differential Effects of Calcium-Channel Blockers on Vascular Endothelial Function in Patients With Coronary Spastic Angina
}

\author{
Yoichi Miwa, MD; Hiroyuki Masai, MD*; Masatoshi Shimizu, MD*
}

\begin{abstract}
Background: The effects of the 3 classes of L-type calcium-channel blockers (CCBs) on vascular endothelial function have not been clarified in patients with coronary vasospasm.

Methods and Results: Twenty-five normotensive patients (age 64.0 \pm 1.4 years) with coronary vasospasm were randomly treated for 3 months with benidipine, diltiazem, and verapamil, which belong to the dihydropyridine, benzothiazepine, and phenylalkylamine classes of CCBs, respectively. Endothelium-dependent flow-mediated dilatation (FMD), endothelium-independent nitroglycerin-induced dilatation in the brachial arteries, and plasma cyclic guanosine 3',5'-monophosphate (cGMP), a nitric-oxide-related product, were assessed before and after treatment. At baseline, the patients with vasospasm had significantly lower FMD as compared with normal subjects $(n=8)$. Blood pressure did not differ among the 3 groups before and after treatment. Benidipine significantly increased FMD (from $4.7 \pm 0.6$ to $7.4 \pm 1.1 \%, \mathrm{P}<0.05$ ) and plasma cGMP levels. In contrast, neither diltiazem nor verapamil affected FMD and cGMP levels. None of the treatments affected nitroglycerin-induced dilatation.

Conclusions: Benidipine, but not diltiazem or verapamil, improves endothelial dysfunction beyond blood pressure lowering effects in patients with coronary vasospasm. Upregulation of the nitric oxide-cGMP system by benidipine may partly contribute to the improvement. The dihydropyridine class may be more beneficial for vascular endothelial function than the non-dihydropyridine classes of CCBs. (Circ J 2009; 73: 713-717)
\end{abstract}

Key Words: Benidipine; Calcium-channel blockers; Coronary artery disease; Endothelial function; Vasospasm

C oronary vasospasm plays an important role in the pathogenesis of not only variant angina but also coronary heart disease in general, including acute coronary syndrome ${ }^{-4}$ In humans, coronary vasospasm is induced by acetylcholine, histamine, ergonovine, or serotonin, all of which cause vasodilation by virtue of the release of nitric oxide (NO) when the endothelium is intact t $^{5-9}$ Therefore, vascular endothelial dysfunction is thought to be important in the pathogenesis of coronary spasm. Recent studies have shown that endothelial NO activity is decreased in patients with coronary spastic angina (CSA), leading to impaired flow-mediated dilation (FMD) in systemic arteries as well as coronary arteries ${ }^{10-12}$ Thus, protecting vascular endothelial function is critical in treating coronary spasm.

Calcium-channel blockers (CCBs) are recommended as first-line therapy in angina patients with coronary spasm ${ }^{13}$ Recent studies have demonstrated that certain CCBs improve vascular endothelial dysfunction! ${ }^{14,15}$ There are 3 classes of voltage-dependent L-type CCBs: dihydropyridines, benzothiazepines and phenylalkylamines, broadly classified according to chemical structure!6,17 The cardiovascular profile,

(Received February 19, 2008; revised manuscript received November 17, 2008; accepted November 25, 2008; released online February 17, 2009)

Department of Internal Medicine, *Department of Cardiology, National Hospital Organization Kobe Medical Center, Kobe, Japan

Mailing address: Yoichi Miwa, MD, Department of Internal Medicine, National Hospital Organization Kobe Medical Center, 3-1-1 NishiOchiai, Suma-ku, Kobe 654-0155, Japan. E-mail: yomiwa-circ@umin. ac.jp

All rights are reserved to the Japanese Circulation Society. For permissions, please e-mail: cj@j-circ.or.jp including vasoselectivity, inhibition of vascular smooth muscle contraction and reduction of myocardial contractility, varies with the different types of CCB ${ }^{18}$ However, it is still unknown whether in patients with CSA the beneficial effects on vascular endothelial function are common among the CCBs.

We designed the present study to compare the effects of the 3 classes of L-type CCBs on endothelial-dependent FMD of the brachial arteries in patients with CSA. For comparison, we used benidipine, diltiazem and verapamil, which belong to the dihydropyridine, benzothiazepine, and phenylalkylamine classes of L-type CCBs, respectively.

\section{Methods}

\section{Study Population}

From October 2001 to December 2004, 84 patients were diagnosed with CSA by performing spasm provocation tests. Of these, the present study included 25 consecutive patients with CSA (mean age 64.0 \pm 1.4 years, 8 men) in whom spontaneous angina occurred at rest. All the patients with CSA had angiographically normal coronary arteries and showed angiographically documented coronary spasm associated with ischemic ST segment changes after intracoronary injection of acetylcholine, as previously reported? Coronary spasm was defined as an abnormal contraction $(\geq 90 \%)$ of an epicardial coronary artery associated with an attack of chest pain and ischemic ECG changes (ST depression $>0.1 \mathrm{mV}$ or ST elevation $>0.2 \mathrm{mV}$ in more than 2 leads). We defined multivessel coronary spasm as spasm of 2 or 3 of the 3 major epicardial coronary arteries (right coronary artery (RCA), left anterior descending (LAD) or left circum- 
Table 1. Clinical Characteristics of Study Subjects

\begin{tabular}{lcc}
\hline & $\begin{array}{c}\text { Controls } \\
(\mathrm{n}=8,2 \mathrm{men})\end{array}$ & $\begin{array}{c}\text { CSA } \\
(\mathrm{n}=25,8 \mathrm{men})\end{array}$ \\
\hline Age (years) & $57.7 \pm 4.3$ & $64.0 \pm 1.4$ \\
Body mass index $\left(\mathrm{kg} / \mathrm{m}^{2}\right)$ & $22.8 \pm 0.8$ & $24.1 \pm 0.8$ \\
Systolic blood pressure $(\mathrm{mmHg})$ & $124 \pm 6$ & $131 \pm 3$ \\
Diastolic blood pressure $(\mathrm{mmHg})$ & $77 \pm 3$ & $76 \pm 3$ \\
Heart rate (beats/min) & $73 \pm 4$ & $70 \pm 2$ \\
Total cholesterol $(\mathrm{mg} / \mathrm{dl})$ & $190 \pm 10$ & $208 \pm 6$ \\
Triglycerides $(\mathrm{mg} / \mathrm{dl})$ & $103 \pm 16$ & $122 \pm 9$ \\
HDL-cholesterol $(\mathrm{mg} / \mathrm{dl})$ & $50 \pm 4$ & $55 \pm 4$ \\
\hline
\end{tabular}

Values are expressed as mean \pm SEM.

CSA, coronary spastic angina; HDL, high-density lipoprotein.

flex artery). The study also included 8 control subjects (mean age $57.7 \pm 4.3$ years, 2 men). The control subjects underwent diagnostic cardiac catheterization for evaluation of chest pain. They had angiographically normal coronary arteries and did not show coronary spasm after intracoronary injection of acetylcholine. Control subjects were studied to compare the baseline data with those in patients with CSA. All the subjects were normotensive $(<160 / 100 \mathrm{mmHg})$, did not have either diabetes (fasting blood sugar $<110 \mathrm{mg} / \mathrm{dl}$ and $\mathrm{HbA} 1 \mathrm{c}<5.8 \%$ ) or a smoking habit, and had a plasma total cholesterol $<240 \mathrm{mg} / \mathrm{dl}$. These risk factors for atherosclerosis have been shown to be associated with impaired endothelium-dependent vasodilation. All the female patients were postmenopausal and were not on hormone replacement therapy. None of the study subjects had a history of previous myocardial infarction, congestive heart failure or other serious diseases. Written informed consent was given by all participants, and the hospital's Ethics Committee approved the study protocol.

\section{Study Protocol}

Consecutive patients with CSA were randomized to 1 of 3 CCB groups: benidipine $8 \mathrm{mg} /$ day ( 2 men, 7 women; age $63.5 \pm 2.2$ years), diltiazem $200 \mathrm{mg} /$ day (4 men, 4 women; age: $65.0 \pm 2.2$ years) and verapamil $120 \mathrm{mg} /$ day $(2 \mathrm{men}$, 6 women; age: $62.3 \pm 2.9$ years). Medication was continued for 3 months. No other medications affecting vascular tone or endothelial function, such as nitrates, angiotensin-converting enzyme inhibitors, angiotensin II receptor blocker, aspirin or hydroxymethylglutaryl coenzyme A reductase inhibitors (statins), were administered to any of the study patients. Measurement of blood pressure, pulse rate and flow-dependent vasodilation, and blood sampling were performed before and after 3 months' treatment. All medications except CCBs were withdrawn for at least $24 \mathrm{~h}$ before the measurements were taken.

\section{Vascular Function}

FMD and dilatation by nitroglycerin were assessed according to a method described previously 19 In brief, the diameter of the right brachial artery was measured by highresolution ultrasound cardiography (Aplio, Toshiba, Tokyo, Japan). To produce reactive hyperemia, blood flow to the forearm was prevented by inflation of the cuff on the arm to at least $50 \mathrm{mmHg}$ above systolic pressure for $5 \mathrm{~min}$. The diameter was measured from the anterior to the posterior interface between the media and adventitia, and it was calculated from 3 cardiac cycles synchronized with the R-wave peaks on ECG. Measurement at $60 \mathrm{~s}$ after cuff release showed the maximal dilatation. The diameter change was expressed as the percent change relative to diameter during the initial resting scan (\%FMD); 15 min later, a resting scan was recorded and a sublingual nitroglycerin spray $(300 \mu \mathrm{g}$, Toa Eiyo Co, Tokyo, Japan) was administered and $3 \mathrm{~min}$ later, the last scan was performed. The diameter change was expressed as percent dilatation by nitroglycerin. All arterial diameters were measured by an observer who was unaware of the subject grouping.

\section{Blood Sampling}

Blood was sampled on the morning of the ultrasound examination before and after treatment. Serum total cholesterol, triglyceride and high-density lipoprotein cholesterol levels were measured. The concentration of plasma cyclic guanosine 3',5'-monophosphate (cGMP) was also measured by radioimmunoassay (SRL Co, Tokyo, Japan).

\section{Statistical Analysis}

The data were compared using ANOVA or unpaired t-test. A value of $\mathrm{P}<0.05$ was considered significant. All data are expressed as mean \pm SEM.

\section{Results}

\section{Comparison of Patients and Control Subjects}

There were no differences between groups when compared for age, body mass index, systolic and diastolic blood pressures, heart rate, total cholesterol, triglyceride and highdensity lipoprotein-cholesterol (Table 1). Brachial artery

\section{a) FMD}

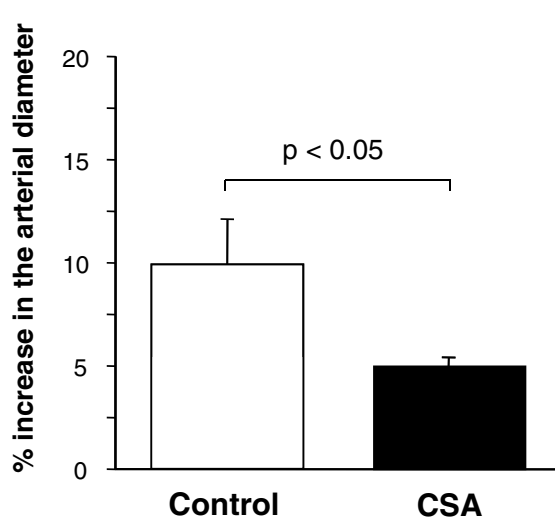

b) NTG-induced dilatation

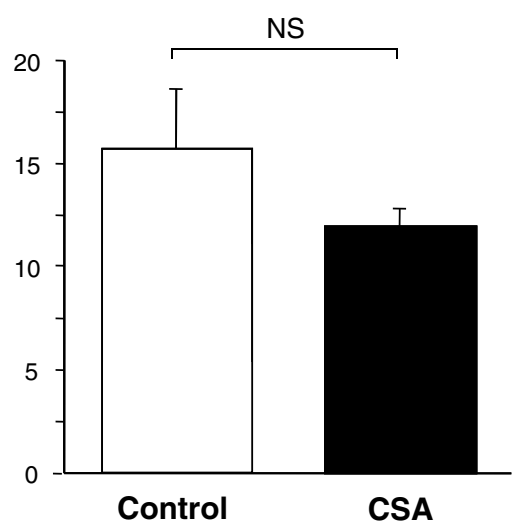

Figure 1. Percent increase in vessel diameter induced by flow-mediated dilatation (FMD, a) or sublingual nitroglycerin (NTG, b) treatment in control and patients with coronary spastic angina (CSA). Values are mean \pm SEM. 
Table 2. Clinical Characteristics of Patients With CSA

\begin{tabular}{|c|c|c|c|c|c|c|}
\hline & \multicolumn{2}{|c|}{$\begin{array}{l}\text { Benidipine group } \\
\quad(\mathrm{n}=9,2 \text { men })\end{array}$} & \multicolumn{2}{|c|}{$\begin{array}{l}\text { Diltiazem group } \\
(\mathrm{n}=8,4 \text { men })\end{array}$} & \multicolumn{2}{|c|}{$\begin{array}{l}\text { Verapamil group } \\
(\mathrm{n}=8,2 \text { men })\end{array}$} \\
\hline & Before & After & Before & After & Before & After \\
\hline Age (years) & $63.5 \pm 2.2$ & - & $65.0 \pm 2.2$ & - & $62.3 \pm 2.9$ & - \\
\hline Body mass index $\left(\mathrm{kg} / \mathrm{m}^{2}\right)$ & $26.0 \pm 2.2$ & - & $24.0 \pm 1.1$ & - & $23.4 \pm 1.7$ & - \\
\hline Systolic blood pressure (mmHg) & $131 \pm 5$ & $123 \pm 7$ & $135 \pm 5$ & $134 \pm 7$ & $127 \pm 4$ & $124 \pm 6$ \\
\hline Diastolic blood pressure $(\mathrm{mmHg})$ & $79 \pm 4$ & $78 \pm 6$ & $76 \pm 5$ & $84 \pm 6$ & $72 \pm 4$ & $80 \pm 4$ \\
\hline Heart rate (beats/min) & $67 \pm 5$ & $67 \pm 5$ & $69 \pm 3$ & $65 \pm 4$ & $74 \pm 2$ & $69 \pm 2$ \\
\hline Total cholesterol (mg/dl) & $205 \pm 14$ & - & $195 \pm 4$ & - & $216 \pm 8$ & - \\
\hline Triglycerides (mg/dl) & $119 \pm 21$ & - & $106 \pm 12$ & - & $136 \pm 18$ & - \\
\hline HDL-cholesterol (mg/dl) & $59 \pm 8$ & - & $48 \pm 9$ & - & $57 \pm 6$ & - \\
\hline \multicolumn{7}{|l|}{ Involved artery in provocation test } \\
\hline Left main artery & $0(0 \%)$ & - & $0(0 \%)$ & - & $0(0 \%)$ & - \\
\hline LAD & $7(78 \%)$ & - & $6(75 \%)$ & - & $6(75 \%)$ & - \\
\hline LCX & $4(44 \%)$ & - & $4(50 \%)$ & - & $3(38 \%)$ & - \\
\hline RCA & $7(78 \%)$ & - & $7(88 \%)$ & - & $5(63 \%)$ & - \\
\hline Multivessel spasm & $6(67 \%)$ & - & $5(63 \%)$ & - & $4(50 \%)$ & - \\
\hline
\end{tabular}

Values are mean \pm SEM.

LAD, left anterior descending artery; LCX, left circumflex artery; RCA, right coronary artery. Other abbreviations see in Table 1.

\section{a) FMD}

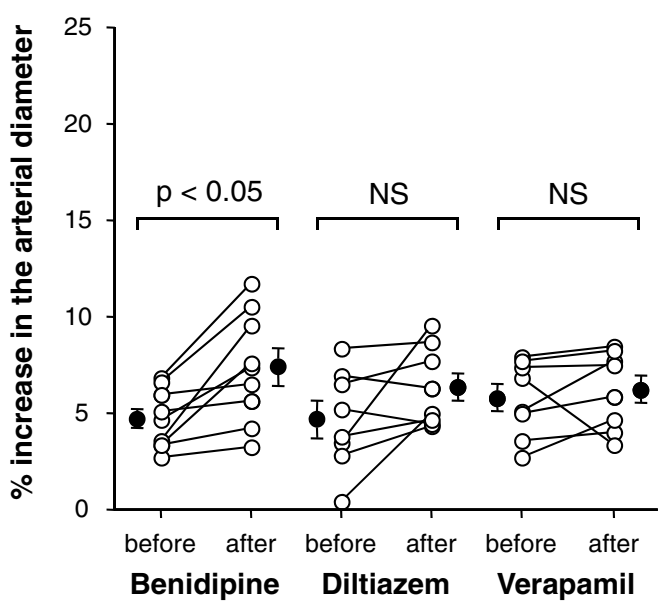

b) NTG-induced dilatation

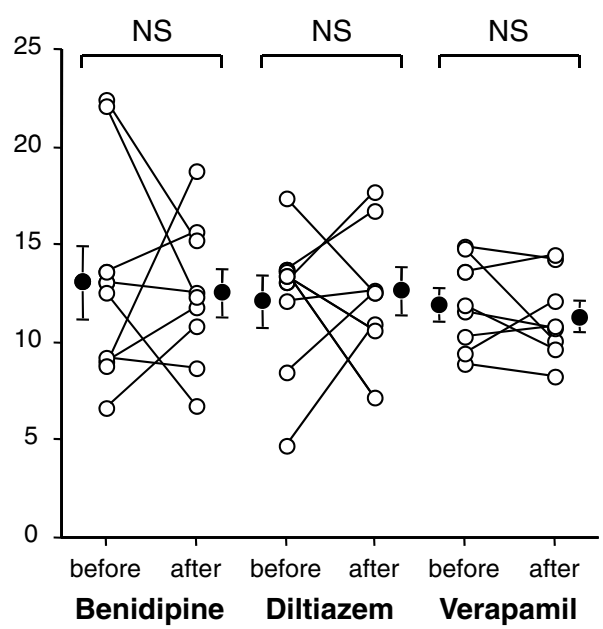

Figure 2. Percent increase in vessel diameter induced by flow-mediated dilatation (FMD, a) or sublingual nitroglycerin (NTG, b) in patients with coronary spastic angina before and after 3-month treatment with benidipine, diltiazem or verapamil. Values are mean \pm SEM.

FMD was significantly impaired in patients with CSA compared with control subjects $(4.8 \pm 0.6 \%$ vs $9.9 \pm 2.1 \%, \mathrm{P}<0.05$; Figure 1). In contrast, the difference in nitroglycerin-induced dilatation between the patients and control group was not significant $(11.8 \pm 0.9 \%$ vs $15.6 \pm 2.9 \%$, NS; Figure 1).

\section{Effects of CCBs on Vascular Function}

At baseline, blood pressure, heart rate, total cholesterol, triglyceride and high-density lipoprotein cholesterol did not differ among the 3 treatment groups. After 3 months' treatment, systolic and diastolic blood pressures did not differ. None of the CCBs administered caused significant changes in blood pressure after treatment (Table 2). Both diltiazem and verapamil decreased heart rate after treatment, but the decreases showed no significant differences (Table 2). Of the patients among the 3 treatment groups, the LAD and RCA were commonly involved in the spasm provocation tests (Table 2). Throughout the study, 2 patients in each of the diltiazem and verapamil groups had an anginal attack during the treatment. None of the patients in the benidipine group had anginal attacks during the treatment.

Brachial artery FMD at baseline did not differ among the 3 groups. Benidipine significantly increased FMD after treatment compared with baseline $(4.7 \pm 0.6 \%$ to $7.4 \pm 1.1 \%$, $\mathrm{P}<0.05)$. In contrast, there were no significant differences between the pre- and post-treatment FMD values in the diltiazem $(4.7 \pm 1.3 \%$ to $6.3 \pm 0.8 \%, \mathrm{NS})$ and verapamil groups $(5.8 \pm 0.8 \%$ to $6.2 \pm 0.8 \%$, NS) (Figure 2a). None of the CCBs affected nitroglycerin-induced dilatation (benidipine: $13.0 \pm$ $2.2 \%$ to $12.5 \pm 1.4 \%, \mathrm{NS}$; diltiazem: $12.1 \pm 1.6 \%$ to $12.6 \pm 1.4 \%$, NS; verapamil: $11.9 \pm 0.8 \%$ to $11.3 \pm 0.7 \%$, NS) (Figure 2b).

\section{Effects of CCBs on Plasma cGMP Levels}

Plasma cGMP levels were significantly elevated after treatment with benidipine $(2.3 \pm 0.4 \mathrm{pmol} / \mathrm{ml}$ to $3.4 \pm 0.5 \mathrm{pmol} / \mathrm{ml}$, $\mathrm{P}<0.05$ ), whereas the changes from baseline were not significant with diltiazem $(2.8 \pm 0.3 \mathrm{pmol} / \mathrm{ml}$ to $2.7 \pm 0.4 \mathrm{pmol} / \mathrm{ml}$, NS) or verapamil $(3.7 \pm 0.9 \mathrm{pmol} / \mathrm{ml}$ to $3.0 \pm 0.4 \mathrm{pmol} / \mathrm{ml}, \mathrm{NS})$ (Figure 3). 


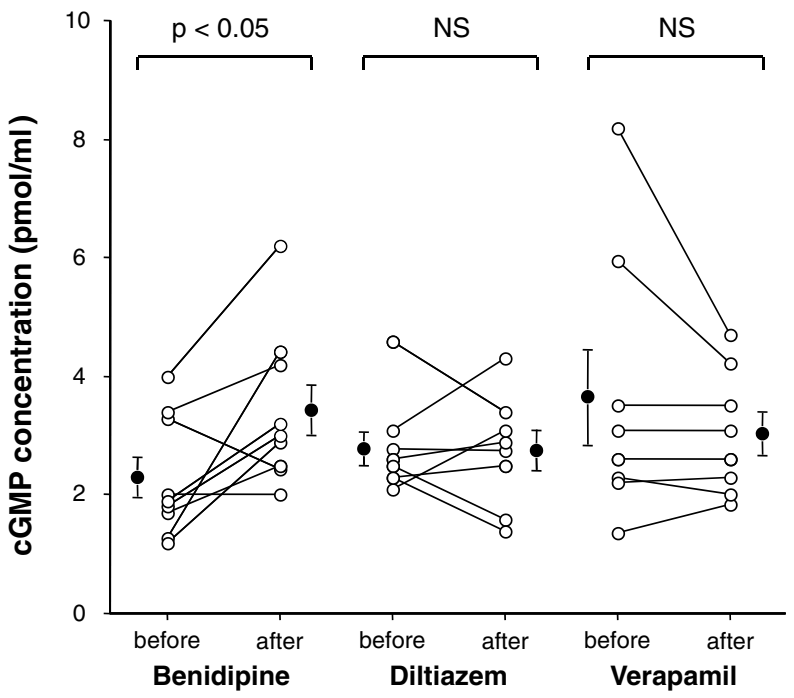

Figure 3. Plasma cyclic guanosine 3',5'-monophosphate (cGMP) levels in patients with coronary spastic angina before and after 3-month treatment with benidipine, diltiazem or verapamil. Values are mean \pm SEM.

\section{Discussion}

CCBs are widely used to treat patients with CSA. The coronary smooth muscle of patients with vasospastic angina is hypercontractile to various stimuli such as histamine ${ }^{20}$ ergonovine? serotonin, etc. In addition to an altered contractile response of coronary smooth muscle, impaired endothelial function, especially NO function, is associated with coronary vasospasm. ${ }^{21,22}$ In the present study, we showed that endothelium-dependent FMD was decreased in vasospastic angina patients compared with control subjects, thus confirming the impaired vascular endothelial function in these patients and in agreement with previous reports ${ }^{11,12}$ Furthermore, of the $3 \mathrm{CCBs}$, only benidipine, a dihydropyridine, provided a significant improvement in endotheliumdependent FMD and plasma cGMP concentration in patients with coronary vasospasm. Diltiazem and verapamil, nondihydropyridine-type $\mathrm{CCBs}$, had no effect on FMD or cGMP. These findings suggest that different types of CCBs have different effects on vascular endothelial function in patients with CSA.

Endothelium-dependent FMD of the brachial artery evaluated by high-resolution ultrasound has been studied extensively in recent years ${ }^{19}$ It is believed to reflect vascular NO function, because an increase in wall shear stress due to the increase in blood flow activates endothelial NO synthase and subsequent production of NO. NO evokes vasorelaxation by activating guanylate cyclase, thereby increasing cGMP concentration. Thus, endothelium-dependent FMD can be imaged and quantified as an index of vasomotor function. Endothelial dysfunction can be regarded as a systemic disorder and thus measured in different vascular beds. The method for measuring FMD used in the present study is clinically attractive because it is noninvasive and allows repeated measurements over time for studying the effectiveness of various interventions that may affect vascular health. A growing body of evidence suggests that endothelial dysfunction is associated with cardiovascular events, so assessment of FMD may be useful for predicting the likelihood of such events? ${ }^{23}$
This is the first report to show different effects of CCBs on vascular endothelial function in patients with CSA. Although a number of reports have focused on endothelial function, a lack of consensus exists concerning the utility of calcium antagonists in the management of endothelial dysfunction 24 Of the 3 CCBs studied, only benidipine significantly improved endothelium-dependent FMD and cGMP. Benidipine is a dihydropyridine CCB developed in Japan. It has a slow-onset, long-lasting action with high affinity and selectivity for blood vessels ${ }^{25}$ and has been widely used to treat angina pectoris and hypertension.

The precise mechanism by which benidipine improves endothelial dysfunction is presently unclear. To our knowledge, L-type calcium channels have not been demonstrated in vascular endothelial cells. Accordingly, the effect of benidipine on endothelial function is most likely a calciumchannel-independent action. The fact that diltiazem and verapamil, the other L-type CCBs, showed no such effect lend support for that possibility. In this study, which included normotensive patients, none of the $3 \mathrm{CCBs}$ had significant effects on blood pressure. Furthermore, blood pressure at the end of 3 months of treatment did not differ among the 3 groups. Therefore, the blood-pressure-lowering effect of benidipine is of little importance in the improvement of endothelial function and increase in cGMP, to which some secondary mechanisms may contribute.

There are some possible explanations for the observation that only benidipine improved endothelial function. The first is direct enhancement of NO production. The increase in plasma cGMP supports the hypothesis that benidipine improves NO function. Previous studies using animal models have demonstrated that benidipine increases endothelial NO synthase gene expression and enhances NO production.6-28 A recent study has shown that benidipine improves decreases in tetrahydrobiopterin, an essential cofactor of NO synthase, in the plasma and kidneys, leading to reduction of proteinuria in a rat model of type II diabetes ${ }^{28}$ Preservation of tetrahydrobiopterin levels by benidipine may be partly involved in enhancement of NO production. In contrast to benidipine, apparent enhancement of NO production has not been reported for diltiazem ${ }^{15}$ or verapamil 29 The second possible explanation is antioxidation. Numerous reports have referred to the antioxidant effect of benidipine 30 which is more potent than that of diltiazem or verapamil31 Decreased free radicals contribute to the prolongation of NO. This antioxidant effect of benidipine may contribute to the improvement of endothelial function. The third reason is differences in the cardiovascular profile, including vasoselectivity, inhibition of vascular smooth muscle contraction and reduction of myocardial contractility, among CCBs $!^{18}$ More particularly, phenylalkylamine and benzothiazepines have much in common, showing a similar selectivity for heart and vessels and a relatively large reduction in myocardial contractility, whereas dihydropyridines are characterized by a high degree of vasoselectivity. Previous studies comparing the impact of benidipine on the myocardium and coronary arteries indicated that the compound exhibited vasoselectivity, more remarkable than either diltiazem or verapamil.25 This vasoselectivity combined with the aforementioned mechanisms is likely to improve endothelial function.

In the present study, anginal attacks were completely suppressed only by benidipine during the treatment. A retrospective cohort study in Japanese patients demonstrated a significant improvement in prognosis with benidipine compared with other CCBs, as well as its utility in long-term 
treatment of CSA 32 The beneficial effect of benidipine on vascular endothelial function as observed in the present study may be associated with an improved prognosis for patients with CSA.

\section{Study Limitations}

The prevalence of CSA is commonly higher in male patients than in female patients. In the present study, however, female subjects with CSA were predominant in the benidipine and verapamil groups. Many male smokers diagnosed with CSA were excluded from the study, which may explain the higher proportion of women. The small number of patients analyzed and the lack of data concerning other dihydropyridine CCBs hinder us from determining whether the favorable effect on endothelial function is peculiar to benidipine or common among dihydropyridine CCBs. This should be further investigated and future studies should also focus on the association between the time course of FMD change and cardiovascular events.

\section{Conclusions}

Benidipine, but not diltiazem or verapamil, protects against vascular endothelial dysfunction in patients with CSA. This property is independent of its blood-pressure-lowering effect and may be partly due to upregulation of the NO-cGMP system. Thus, CCBs have differential effects on vascular endothelial function in patients with CSA. Dihydropyridinetype CCBs may be more beneficial to vascular endothelial function than non-dihydropyridine-type CCBs, but it needs to be clarified in future studies whether this beneficial effect is common among the dihydropyridine-type CCBs.

\section{Acknowledgment}

We are grateful to Dr Masahito Kawata (Department of Cardiology, Akashi Medical Center) for valuable suggestions about the planning of the study.

\section{References}

1. Hillis LD, Braunwald E. Coronary-artery spasm. N Engl J Med 1978; 299: 695-702.

2. Conti CR. Coronary artery spasm and myocardial infarction. $N$ Engl J Med 1983; 309: 238-239.

3. Maseri A, Davies G, Hackett D, Kaski JC. Coronary artery spasm and vasoconstriction: The case for a distinction. Circulation 1990; 81: $1983-1991$.

4. Kim PJ, Seung KB, Kim DB, Her SH, Shin DI, Jang SW, et al. Clinical and angiographic characteristics of acute myocardial infarction caused by vasospastic angina without organic coronary heart disease. Circ J 2007; 71: 1383-1386.

5. Yasue H, Horio Y, Nakamura N, Fujii H, Imoto N, Sonoda R, et al. Induction of coronary spasm by acetylcholine in patients with variant angina: Possible role of the parasympathetic nervous system in the pathogenesis of coronary artery spasm. Circulation 1986; 74: $955-$ 963.

6. Okumura K, Yasue H, Matsuyama K, Matsuyama K, Morikami Y, Ogawa $\mathrm{H}$, et al. Effect of $\mathrm{H}_{1}$ receptor stimulation on coronary artery diameter in patients with variant angina: Comparison with effect of acetylcholine. J Am Coll Cardiol 1991; 17: 338-345.

7. Yokoyama M, Akita H, Hirata K, Usuki S, Fukuzaki H, Itoh H, et al. Supersensitivity of isolated coronary artery to ergonovine in a patient with variant angina. Am J Med 1990; 89: 507-515.

8. McFadden EP, Clarke JG, Davies GJ, Kaski JG, Haider MD, Maseri A. Effect of intracoronary serotonin on coronary vessels in patients with stable angina and patients with variant angina. $N$ Engl J Med 1991; 324: 648-654

9. Moncada S, Palmer RM, Higgs EA. Nitric oxide: Physiology, pathophysiology, and pharmacology. Pharmacol Rev 1991; 43: 109-142.

10. Kugiyama K, Yasue H, Okumura K, Ogawa H, Fujimoto K, Nakao K, et al. Nitric oxide activity is deficient in spasm arteries of patients with coronary spastic angina. Circulation 1996; 94: 266-271.

11. Kugiyama K, Ohgushi M, Motoyama T, Sugiyama S, Ogawa H, Yoshimura M, et al. Nitric oxide-mediated flow-dependent dilation is impaired in coronary arteries in patients with coronary spastic angina. J Am Coll Cardiol 1997; 30: 920-926.

12. Motoyama T, Kawano H, Kugiyama K, Okumura K, Ohgushi M, Yoshimura M, et al. Flow-mediated, endothelium-dependent dilatation of the brachial arteries is impaired in patients with coronary spastic angina. Am Heart J 1997; 133: 263-267.

13. Gibbons RJ, Chatterjee K, Daley J, Douglas JS, Fihn SD, Gardin JM, et al. ACC/AHA/ACP-ASIM guidelines for the management of patients with chronic stable angina: Executive summary and recommendations: A Report of the American College of Cardiology/American Heart Association Task Force on Practice Guidelines (Committee on Management of Patients with Chronic Stable Angina). Circulation 1999; 99: 2829-2848.

14. Dohi Y, Kojima M, Sato K. Benidipine improves endothelial function in renal resistance arteries of hypertensive rats. Hypertension 1996; 28: $58-63$.

15. Zhang X, Hintze TH. Amlodipine releases nitric oxide from canine coronary microvessels: An unexpected mechanism of action of a calcium channel-blocking agent. Circulation 1998; 97: 576-580.

16. Vanhoutte PM. The expert committee of the World Health Organization on classification of calcium antagonists: The viewpoint of the rapporteur. Am J Cardiol 1987; 59: 3A-8A

17. Opie LH, Buhler FR, Fleckenstein A, Hansson L, Harrison DC, PooleWilson PA, et al. International Society and Federation of Cardiology: Working Group on Classification of Calcium Antagonists for Cardiovascular Disease. Am J Cardiol 1987; 60: 630-632.

18. Taira N. Differences in cardiovascular profile among calcium antagonists. Am J Cardiol 1987; 59: 24B-29B.

19. Corretti MC, Anderson TJ, Benjamin EJ, Celermajer D, Charbonneau F, Creager MA, et al. Guidelines for the ultrasound assessment of endothelial-dependent flow-mediated vasodilation of the brachial artery. J Am Coll Cardiol 2002; 39: 257-265.

20. Kalsner S, Richards R. Coronary arteries of cardiac patients are hyperreactive and contain stores of amines: A mechanism for coronary spasm. Science 1984; 223: 1435-1437.

21. Shimokawa H. Cellular and molecular mechanisms of coronary artery spasm: Lessons from animal models. Jpn Circ J 2000; 64: 1-12.

22. Kaneda H, Taguchi J, Kuwada Y, Hangaishi M, Aizawa T, Yamakado $\mathrm{M}$, et al. Coronary artery spasm and the polymorphisms of the endothelial nitric oxide synthase gene. Circ J 2006; 70: 409-413.

23. Lerman A, Zeiher AM. Endothelial function: Cardiac events. Circulation 2005; 111: 363-368.

24. Widlansky ME, Gokce N, Keaney JF Jr, Vita JA. The clinical implications of endothelial dysfunction. $J$ Am Coll Cardiol 2003; 42: $1149-1160$

25. Karasawa A, Kubo K. Calcium antagonistic effects and the in vitro duration of actions of KW-3049, a new 1,4-dihydropyridine derivative, in isolated canine coronary arteries. Jpn J Pharmacol 1988; 47: $35-44$.

26. Kobayashi N, Kobayashi K, Hara K, Higashi T, Yanaka H, Yagi S, et al. Benidipine stimulates nitric oxide synthase and improves coronary circulation in hypertensive rats. Am J Hypertens 1999; 12: $483-$ 491.

27. Yamashita T, Kawashima S, Ozaki M, Rikitake Y, Hirase T, Inoue N, et al. A calcium channel blocker, benidipine, inhibits intimal thickening in the carotid artery of mice by increasing nitric oxide production. J Hypertens 2001; 19: 451-458.

28. Okumura M, Masada M, Yoshida Y, Shintaku H, Hosoi M, Okada N, et al. Decrease in tetrahydrobiopterin as a possible cause of nephropathy in type II diabetic rats. Kidney Int 2006; 70: 471-476.

29. Xu B, Xiao-hong L, Lin G, Queen L, Ferro A. Amlodipine, but not verapamil or nifedipine, dilates rabbit femoral artery largely through a nitric oxide- and kinin-dependent mechanism. Br J Pharmacol 2002; 136: $375-382$.

30. Nomura S, Shouzu A, Omoto S, Nishikawa M, Iwasaka T. Benidipine improves oxidized LDL-dependent monocyte and endothelial dysfunction in hypertensive patients with type 2 diabetes mellitus. J Hum Hypertens 2005; 19: 551-557.

31. Yao K, Ina Y, Nagashima K, Ohmori K, Ohno T. Antioxidant effects of calcium antagonists in rat brain homogenates. Biol Pharm Bull 2000; 23: 766-769.

32. Ito A, Fukumoto Y, Shimokawa H. Changing characteristics of patients with vasospastic angina in the era of new calcium channel blockers. J Cardiovasc Pharmacol 2004; 44: 480-485. 